\title{
Experimental and Numerical Modeling of Screws Used for Rigid Internal Fixation of Mandibular Fractures
}

\author{
Naresh Chaudhary, ${ }^{1}$ Scott T. Lovald, ${ }^{2}$ Jon Wagner, ${ }^{3}$ Tariq Khraishi, ${ }^{2}$ and Bret Baack ${ }^{3}$ \\ ${ }^{1}$ Manufacturing Engineering Program, University of New Mexico, Albuquerque, NM 87131, USA \\ ${ }^{2}$ Mechanical Engineering Department, University of New Mexico, Albuquerque, NM 87131, USA \\ ${ }^{3}$ Department of Surgery, University of New Mexico, Albuquerque, NM 87131, USA
}

Correspondence should be addressed to Tariq Khraishi, khraishi@unm.edu

Received 1 September 2007; Revised 2 January 2008; Accepted 6 February 2008

Recommended by Ewa Pietka

Experimental and numerical methods are used to explore the stresses generated around bone screws used in rigid internal fixation of mandibular fractures. These results are intended to aid in decisions concerning both the design and the use of these bone screws. A finite element (FE) model of a human mandible is created with a fixated fracture in the parasymphyseal region. The mandibular model is anatomically loaded, and the forces exerted by the fixation plate onto the simplified screws are obtained and transferred to another finite element submodel of a screw implant embedded in a trilaminate block with material properties of cortical and cancellous bone. The stress in the bone surrounding the screw implant is obtained and compared for different screw configurations. The submodel analyses are further compared to and validated with simple axial experimental and numerical screw pull-out models. Results of the screw FE analysis (FEA) submodel show that a unicortical screw of 2.6 mm major diameter and $1.0 \mathrm{~mm}$ pitch will cause less bone damage than a bicortical screw of $2.3 \mathrm{~mm}$ major diameter and $1.0 \mathrm{~mm}$ pitch. The results of this study suggest that bicortical drilling can be avoided by using screws of a larger major diameter.

Copyright (C) 2008 Naresh Chaudhary et al. This is an open access article distributed under the Creative Commons Attribution License, which permits unrestricted use, distribution, and reproduction in any medium, provided the original work is properly cited.

\section{Introduction}

Failure of bone screws used for fracture fixation in trauma surgeries is a significant problem that has been examined previously. Rigid internal fixation (RIF) of mandibular fractures has been a focus of studies on screw performance due to the mandible's load bearing function and the rate of complication seen with these types of surgery. Screw failure in mandibular bone is undesirable as any movement of the mandible in the presence of a foreign body can lead to infection. Tada [1] stated that inappropriate loading can cause excessive stress in the bone around a foreign implant and may result in bone resorption. Screw loosening not only increases the chance of infection at the screw failure site but creates a less stable environment for fracture healing. Murthy [2] and Gabrielli [3] have both stated that stability in the fracture region can aid in defending against infection. Infection reduces oxygenation to the fracture site creating an environment more conducive to fibrous union than bone deposition. The result of this activity is that infection leads to more serious complications including debilitating pain, malunion, nonunion, chronic osteomyelitis, and acquired skeletal deformities [4]. Complications of this nature can in some cases require a second surgery.

The most pertinent metric to measure the success of a bone screw has traditionally been the pullout or holding strength of the screw when seated in bone [5]. In such mechanical assemblies, there will be some sort of internally and/or externally generated forces on these screws that can encourage failure of either the screw or the surrounding bone. Each bone screw has design parameters that may affect the likelihood of screw implant failure. One of the most important considerations is the decision to use bicortical or unicortical fixation. Bicortical fixation utilizes longer screws that are seated within both the buccal and lingual cortices while unicortical fixation uses shorter screws that are seated only in the buccal section of cortical bone. Utilization of bicortical screws stems from the common belief that a bicortically drilled screw can sustain a stronger load before 
failure. However, a bicortical fixation also means longer surgical times and increased chance of complications due to higher probability of interference with the dental segment and the inferior alveolar nerve. Unicortical fixations, onthe other hand, are less time consuming and avoid interference with the dental segment and the inferior alveolar nerve. It is important to have an understanding of the effect of screw length, as well as other design parameters, for a surgeon to make a judicious decision of the level of intrusion necessary to safely fixate a mandibular fracture.

Previous research has yielded many insightful observations into the modes of bone screw failure and the effect of certain design parameters for different types of bone screws. Skinner [6] compared four different types of screws used in transpedicular screw fixation. They observed an increase in the pull-out strength due to an increase in the screw diameter and an increase in displacement before failure resulting from an increase in the screw pitch. Complete failure occurred when a sharp-threaded screw was pulled out one whole pitch distance, an observation also reported by Ryken [7] using cervical plate screws. Another study by Ryken [8] suggested that bicortical screw insertion provides more holding than unicortical insertion while also finding a direct correlation between the bone mineral density (BMD) of the surrounding bone and the screw pull-out strength. Using Casper cervical screws, Maiman [9] observed that cancellous bone remained on screw threads after failure, but that posterior cortical penetration does not improve pull-out strength. With regard to smaller screws used in mandibular and maxilla fracture fixation, Boyle [10] suggested that $2.7 \mathrm{~mm}$ diameter screws do not have an advantage over $2.0 \mathrm{~mm}$ screws when seated in thin porcine rib, while at least three self-tapping threads should be used for maximum retention. A similar conclusion was also reached by Phillips [11]. Although a wealth of information exists on screw pullout studies, there have been no studies that have completed a thorough analysis of screws used in mandibular fracture repair. To the authors' knowledge, this would be the first such study.

The first focus of the current study is to perform screw pull-out using mandibular bone screws in a trilaminate block with sections representing material properties closely resembling two sections/layers of cortical bone sandwiching a section of cancellous bone. This provides a more realistic determination of the effect of bone screw design parameters than using a single layer of continuous material. Screws will be experimentally pulled out of the trilaminate block to observe actual modes of screw failure before a FE model will simulate the experimental testing. The FE model gives flexibility towards discovering the effects of different design parameters on the pull-out strength. This is the first known correlated attempt to perform both experimental and simulated screw pull-out testing on a trilaminate material closely resembling layers of cortical and cancellous bone.

While both experimental testing and finite element analysis of screw loading and failure have received some attention, the natural loading on mandibular implant screws during mastication has not yet been reported. Previous studies have shown that FEA of screw pull-out testing can be both validated by experiment, andit is a useful design tool when looking at stress and strain generated around screw implants [1]. The value of these studies has so far been limited by the generally unknown forces on the screws implants in actual patients.

Recently, work by Cox [12], Fernández [13], Wagner [14], and Lovald $[15,16]$ has shown that finite element analysis (FEA) of the entire mandible can mimic natural human loading on a fractured mandible andcan determine the stress and strain fields within the bone and implant devices as well as the forces generated on the screw implants. Given the size and complexity of these models, simplifications are often required in representing the bone screws. Wagner and Cox neglected the screws, bonding the plate directly to mandibular bone. Lovald used cylinders in place of threaded screws. While these models were able to determine stress in the fixation plate and fracture mobility, they did not yield accurate results pertaining to the stresses in cortical and cancellous bone emanating from a threaded screw.

The second focus of the current study enhances work on both studies of screw pull-out FEA and mandibular fracture fixation FEA by translating three-dimensional forces from a mandibular FE model to a screw FE submodel considering bone screw embedded in a trilaminate bone material. The comparison will use von Mises stress in the cortical bone surrounding the screws. Stress in the bone surrounding the seated screw can lead to screw failure and the complications described previously. Von Misescriterion was chosen in order to be consistent with prior studies of similar nature $[1,12-$ 15]. Using the boundary conditions from the mandibular FEA model, the effect of certain screw design parameters, including bicortical versus unicortical fixation, will once again be explored. To simplify the second part of this study, parameters determined optimal during the first part of the study will be used. Design parameter analysis will be focused on four configurations with differing screw lengths, pitches, and major diameters.

\section{Materials and Methods}

The current study has three components:

(i) validation and design parameter analysis of experimental and numerical screw pull-out from a trilaminate block with properties of cortical and cancellous bone;

(ii) determination of forces applied to screw implants during natural human loading using FEA of a fractured and fixated human mandible;

(iii) application of the determined forces in component (ii) to a numerical analysis submodel of a screw embedded in a trilaminate block from component (i).

The methods section is broken into the three respective subsections. 


\subsection{Experimental and Numerical Analysis of Screw Pull-out}

\subsubsection{Experimental Screw Pull-out}

The experimental tests were done using bone screws embedded in a trilaminate standard polyurethane block. The polyurethane block has two outer cortical layers and a middle cancellous layer, each $3.0 \mathrm{~mm}$ thick, mimicking mandibular bone. The material properties of these layers were synthesized to closely match mandibular bone properties (Pacific Research Laboratories, Inc., Vashon, Wash, USA). The dimensions of the block for all experiments are $15 \mathrm{~mm} \times 15 \mathrm{~mm} \times 9 \mathrm{~mm}$. Apart from having realistic material properties, these "artificial bone" samples are less expensive, exhibit homogenous properties over a layer, and are easy to manipulate for experiment.

After drilling a pilot hole, titanium self-tapping screws were inserted either completely for bicortical seating, or up to the cancellous layer for unicortical seating. Selftapping screws eliminate the separate tapping requirement for surgical screw insertion. The self-tapping screws are provided by the Leibinger Micro Implants (Stryker Corporation, Kalamazoo, Mich, USA).

The pull-out experiments were carried out on an Instron machine (4400R controller model). Figure 1(a) shows the experimental setup. The specimen is held by clamps in a specially designed vise. The screw is held in a jig such that the screw head rests on the seat provided in the jig. This jig is mounted on the stationary end, which is the Instron machine's upper crossbar. The lower crossbar of the Instron, to which the vise is attached, is then gradually pulled down at a speed of $5 \mathrm{~mm} / \mathrm{min}$ till the screw disengages completely from the block. Computer data acquisition recorded all the forces and displacements during the testing.

\subsubsection{Polishing of the Experimental Specimen}

The failure of the screw-bone interface is hypothesized to start long before the screw is completely pulled out of the block. Therefore, to verify the hypothesis, it is important to do a micro examination of bone damage at loads well below the maximum pull-out load encountered. This is done by taking partially pulled specimen and grinding them finely for examination under a high-resolution microscope. Using the mean failure load data from the pull-out experiments, different polished samples were obtained at different loads. A specimen was then ground on various abrasive grits, rough to fine, till the specimen was sectioned in half.

\subsubsection{Numerical Analysis of Screw Pull-out}

\subsubsection{Geometry Creation}

The 3D CAD modeling system Pro/ENGINEER Wildfire (PTC, Needham, Mass, USA) was used to build a model of a trilaminate mandibular bone specimen with an embedded screw implant. Finite element analysis (FEA)

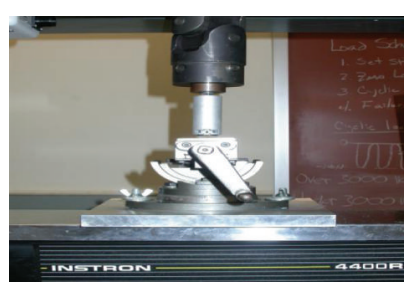

(a)

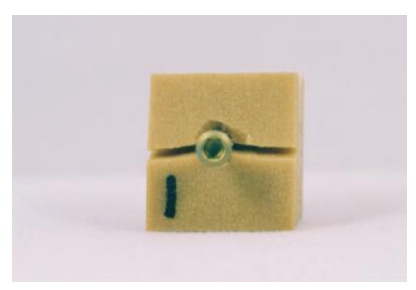

(c)

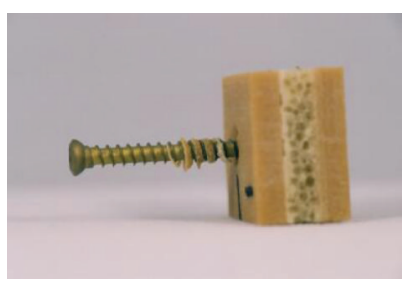

(b)

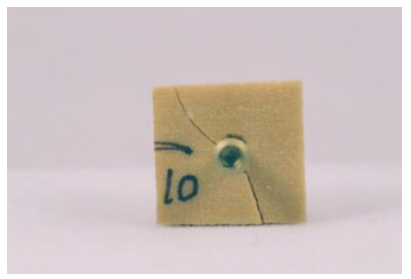

(d)
Figure 1: (a) Experimental setup for the pull-out tests, (b) typical specimen after cylindrical failure with material trapped between screw threads, (c) pull-out specimen with vertical cracks, and (d) pull-out specimen with diagonal cracks.

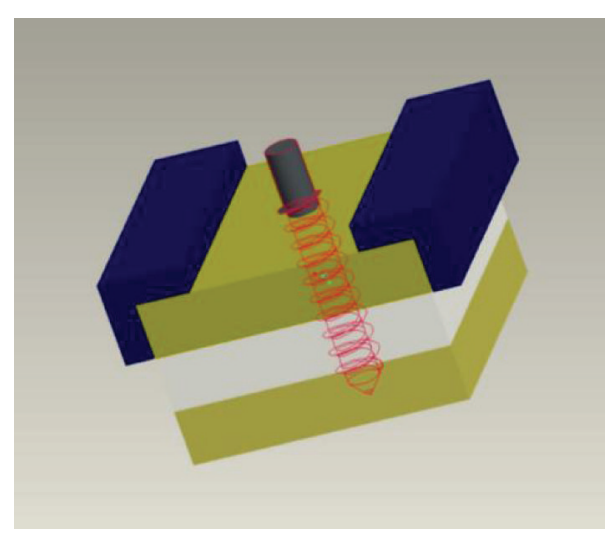

Figure 2: The Pro/E 3D assembly for the screw-pull out finite element analysis.

of a simulated screw pull-out process was carried out using the Pro/Mechanica software, which is companion software to Pro/ENGINEER Wildfire. Geometrical data for the screwswas provided by the Stryker-Leibinger Corp. (Kalamazoo, Mich, USA).

To simplify the model, the trilaminate bone specimen is modeled as a cuboid (Figure 2). The trilaminate block is modeled as a $15 \mathrm{~mm} \times 15 \mathrm{~mm}$ square with three $3 \mathrm{~mm}$ thick layers of outer cortical bone and inner cancellous bone. These layers are perfectly bonded to one another. Aluminum clamps of dimensions $15.0 \mathrm{~mm} \times 3.5 \mathrm{~mm} \times 2.0 \mathrm{~m}$ were placed on the top edges of the block to mimic the experimental vise. The screw hole in the block is a direct replica of the screw geometry to facilitate CAD assembly. Titanium screws were inserted into the drilled blocks and assumedto be perfectly bonded to the block material. 
TABLE 1: Material properties used in the numerical analysis of the screw pull-out.

\begin{tabular}{lcc}
\hline \multicolumn{3}{c}{ Material properties for screw pull-out FEA } \\
\hline & Elastic modulus $(\mathrm{GPa})$ & Poisson's ratio \\
Bone screw & 113.800 & 0.342 \\
Cortical block layer & 1.190 & 0.300 \\
Cancellous block layer & 0.267 & 0.300 \\
Aluminum clamps & 69.000 & 0.300 \\
\hline
\end{tabular}

\subsubsection{Material Properties}

All materials are assumed to be linear elastic and isotropic. The material properties were taken directly from the respective manufacturers of the bone screws and the synthetic trilaminate block material. Table 1 gives the material properties used in the screw pull-out FEA.

\subsubsection{Boundary Conditions}

The boundary conditions for the numerical analysis are meant to mimic the experiment. The top face of the screw was constrained from movement in all directions. A constant force of $600 \mathrm{~N}$ is applied upon the top sides of the aluminum clamps in a downward direction.

The model was solved numerically for various parameters to study the effects of screw pitch, major diameter, and thread depth on the pull-out strength. The parameter values are as follows: major diameter: $2.0,2.3$, and $2.6 \mathrm{~mm}$; pitch: $1.0,1.2$, and $1.4 \mathrm{~mm}$; thread depth: $0.2,0.3$, and $0.4 \mathrm{~mm}$. Each of these parameters was varied during the study using baseline values of $2.3 \mathrm{~mm}$ for the major diameter, $1.0 \mathrm{~mm}$ for the pitch, and $0.3 \mathrm{~mm}$ for the thread depth.

\subsection{FEA of a Fractured Mandible}

\subsubsection{Mandibular FEA Geometry Creation}

Computerized tomography scans of a 22-year-old male were obtained from a Siemens Somatone Sensations Multislice Scanner. The patient had full dentition and normal occlusion. The scans were imported into Mimics 7.3 (Materialise, Ann Arbor, Mich, USA) where thresholding and editing functions were used to create entities for cortical bone, cancellous bone, and the dental segment. Initial graphics exchange specification (IGES) curves were approximated around the volumes and imported into ANSYS 8.0. Volumes were created and subsequently bonded in the symphysis, parasymphysis, body, angle, ramus, coronoid, and condyle regions using their respective IGES curves.

The volumes created were meshed using tetrahedralshaped solid elements. The final mesh of the mandible with hardware consisted of 67434 elements and 107352 nodes. Mesh refinement was used in the plate, screws, fracture region, and the surrounding cortical and cancellous regions until convergence of all pertinent measures was established. A consistent mesh size was used in all analyses. Geometric information from the finite element model was compared to the original CT scan data to ensure model validity. Furthermore, loadings similar to previous studies were mimicked in order to validate stress results. CAD model verification for this study was detailed in Chaudhary [17] and Lovald $[15,18]$.

The fracture was simulated as a $2 \mathrm{~mm}$ thick linear fracture in the parasymphyseal region. The symphysis of the mandible is the region of the junction of the two symmetrical halves near the sagittal plane. Geometrical data for the plate was provided by the Stryker-Leibinger Corp. (Kalamazoo, Mich, USA). The plate analyzed is the 3D Matrix $4 \times 2$ Hole Mini Plate. There is a small amount of clearance between the modeled plate and bone, as in clinical situations. Unicortical screw fixation was used on the superior border while bicortical fixation was used on the inferior border. Screws were simulated as solid cylinders with a diameter of $2.3 \mathrm{~mm}$ that were inserted and bonded into the bone material.

\subsubsection{Material Properties}

The finite element (FE) model of the dentate mandible consists of the following materials: cortical bone, cancellous bone, and dental segment (dentin, enamel, and periodontal ligament). Coordinate systems and orthotropic properties for cortical bone only were designated in each of 12 mandibular volumes created and mentioned previously. Table 2 gives the material properties for the mandibular FEA. The orthotropic cortical bone values were taken from a study by Schwartz-Dabney and Dechow [19]. Isotropic properties for cancellous bone were taken from [13]. The properties for dentin were taken from another finite element study [20], and they correlate well with a study by Craig and Peyton [21]. In the current study, only material properties for dentin are modeled in the dental segment due to its high modulus of elasticity. The fracture region was given properties of initial connective tissue [22] (Young's modulus of $3 \mathrm{MPa}$ and Poisson's ratio of 0.4 ). The properties of titanium plates and screws were taken from another FE study of mandibular angle fractures [12].

\subsubsection{Boundary Conditions}

The bite force used in this FEA was a unilateral molar clench. Muscle force vectors that were experimentally derived for that specific bite are distributed around the mandible. Each force has a direction, area of attachment, and magnitude. The magnitude and direction of muscle forces during the simulated bite were obtained from Korioth et al. [20] and are detailed in Lovald et al. [15]. The data from this reference pertains to the bite of a healthy adult with an intact mandible. It is estimated that the bite force of a patient with a fractured mandible is $60 \%$ of that of a healthy adult [23]. The bite force data was modified accordingly in this study. The muscle attachment areas on the mandible were obtained from [24]. Both condyles and the occlusal surface of the right first molar are restrained from movement in all directions. Figure 3 shows the meshed mandibular model. 
TABLE 2: Material properties used in FEA of the mandible. Orthotropic properties were used for cortical bone, while isotropic properties were used for cancellous bone, dentin, and the titanium plate. The $x$-direction is along the length of the mandible, the $y$-direction is normal to the bone plane, and the $z$-direction is their cross product.

\begin{tabular}{lccccccccc}
\hline Material properties & Symphysis & Parasymphysis & Angle & Ramus & Condyle & Coronoid & Cancellous & Dentin & Titanium \\
\hline$E_{x}(\mathrm{MPa})$ & 20492 & 21728 & 23793 & 24607 & 23500 & 28000 & 7930 & 17600 & 110000 \\
$E_{y}(\mathrm{MPa})$ & 12092 & 12700 & 12757 & 12971 & 12650 & 14000 & 7930 & 17600 & 110000 \\
$E_{z}(\mathrm{MPa})$ & 16350 & 17828 & 19014 & 18357 & 17850 & 17500 & 7930 & 17600 & 110000 \\
$v_{x y}$ & 0.43 & 0.45 & 0.41 & 0.38 & 0.32 & 0.28 & 0.3 & 0.34 & 0.34 \\
$v_{y z}$ & 0.22 & 0.2 & 0.22 & 0.23 & 0.25 & 0.28 & 0.3 & 0.34 & 0.34 \\
$v_{x z}$ & 0.34 & 0.34 & 0.3 & 0.28 & 0.24 & 0.23 & 0.3 & 0.34 & 0.34 \\
$G_{x y}(\mathrm{MPa})$ & 5317 & 5533 & 5493 & 5386 & 5500 & 5750 & 3050 & 6567 & 41045 \\
$G_{y z}(\mathrm{MPa})$ & 4825 & 5083 & 4986 & 5014 & 5150 & 5300 & 3050 & 6567 & 41045 \\
$G_{x z}(\mathrm{MPa})$ & 6908 & 7450 & 7579 & 7407 & 7150 & 7150 & 3050 & 6567 & 41045 \\
\hline
\end{tabular}

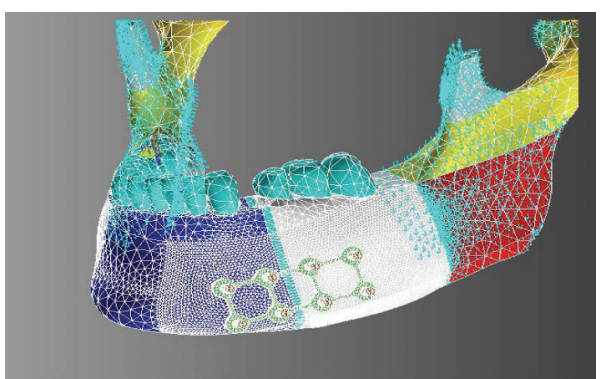

FIGURE 3: Meshed mandibular model showing a parasymphyseal fracture, fixation plates and screws, and different material regions for orthotropic material properties.

\subsection{Submodel FEA of a Threaded Screw}

\subsubsection{Geometry Creation}

Geometry used in the screw FEA submodel is nearly identical to that described in Section 2.1.3.1. To simplify the modeling, the aluminum clamps were not modeled.

\subsubsection{Material Properties}

The material properties in the screw FEA submodel are identical to those of the mandibular FEA from Section 2.2. The outer layers of the trilaminate block are assumedto be orthotropic and are taken directly from the material properties of the parasymphyseal region from the mandibular FEA. To the authors' knowledge, this is the first FE study of screw pull-out using orthotropic cortical bone properties. The inner section of the trilaminate block was assumedto be isotropic andwas given material properties of cancellous bone. The screw implant was given material properties of titanium. All material properties for the screw FEA submodel are given in Table 2 .

\subsubsection{Boundary Conditions}

Thesubmodel trilaminate block was restrained from movement in three directions on its four sides. A force, obtained from the mandibular FEA in Section 2.2, was applied to the

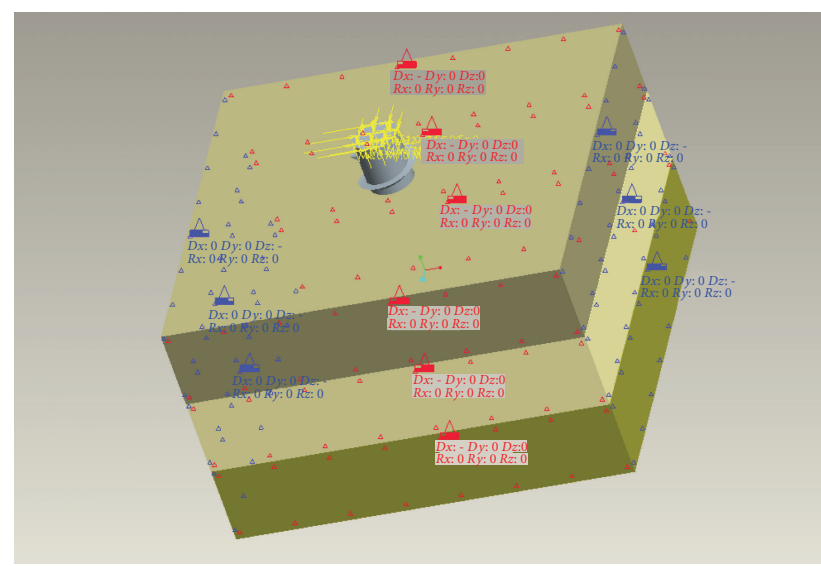

FIgure 4: The 3D Pro/E assembly with boundary conditions. The bone layers are treated as orthotropic.

TABle 3: Different screw configurations used in the FEA screw submodel.

\begin{tabular}{lcc}
\hline Fixation & Major diameter $(\mathrm{mm})$ & Pitch $(\mathrm{mm})$ \\
\hline Bicortical & 2.3 & 1.0 \\
Unicortical & 2.3 & 1.0 \\
Unicortical & 2.3 & 1.2 \\
Unicortical & 2.6 & 1.0 \\
\hline
\end{tabular}

top surface of the screw implant (Figure 4). The force of the particular screw which showed the highest magnitude in the mandibular FEA was the only force applied to the screw FEA submodel. The same constitutive equations as in Sections 2.1.3.2 and 2.2.2 apply also here to the screw pullout submodeling.

This screw FEA submodel setup was utilized to compare different screw design configurations. Table 3 shows the configurations for each analysis. The bicortical screw configuration was considered the base analysis. The other configurations were analyzed to compare with the bicortical screw configuration. A thread depth of $0.3 \mathrm{~mm}$ was held constant throughout all analyses. All screw parameter configurations are commercially available. 


\section{Results}

\subsection{Experimental and Numerical Analysis of Screw Pull-out}

\subsubsection{Experimental Screw Pull-out}

The experimental results were dependent on how the screw exactly failed. Three different modes of failure were observed:

(i) cylindrical failure (Figure 1(b)): in this scenario, the screw pulls out from the block with a significant amount of material trapped between the threads. Samples showing this type of failure have an average pull-out force that is greater than samples in the following scenarios. Samples with cylindrical failure exhibit smooth load-displacement curves, with single maxima (i.e., the lower curve in Figure 5);

(ii) failure with vertical cracks (Figure 1(c)): the block samples show cracks normal to the clamp faces. Wide vertical cracks appear on the top surface of the block. Generally, crackling sounds preceded and accompanied the failure. The cracking of this nature is thought to be due to bending of the block. This assumption is supported by the fact that these cracks were predominant when larger block sizes were used. The curves in this case are jagged with multiple peaks (i.e., multiple local maxima);

(iii) failure with diagonal cracks (Figure 1(d)): these samples show cracks on the top surface of the block that propagate from the circumference of the screw to the corner of the clamp andthey are narrow in comparison to the vertical cracks. The curves in this case are not seen to be as jagged as those of the vertical crack.

The experimental load-displacement curves for the bicortical and unicortical screws show a very consistent trend or characteristic shape for cylindrical type failure (similar to the lower curve in Figure 5). The curves in Figure 5 were obtained using $2.3 \mathrm{~mm}$ major diameter screws with $1.0 \mathrm{~mm}$ pitch. The curve can be divided into three different regions. Region 1 represents a presumably elastic region. Region 2 is predicted to contain the start of plastic deformation through the formation and growth of microcracks. Region 3 is the failure region with macrocracks clearly visible on the surface of the block.

The pull-out experiments were carried out with a sample size of 15 specimens for each of the unicortical and bicortical studies. Results for maximum load and maximum displacement are shown in Table 4. Bicortical fixation is shown to have a higher pull-out strength than unicortical fixation, similar to findings by various works on other types of surgical screws $[7,8]$.

The mean displacement to failure in the case of unicortical pull-out was approximately equal to the pitch of the screw used, similar to findings by Ryken [7]. However, the study by Ryken showed that bicortical screws had a mean displacement to failure greater than unicortical screws

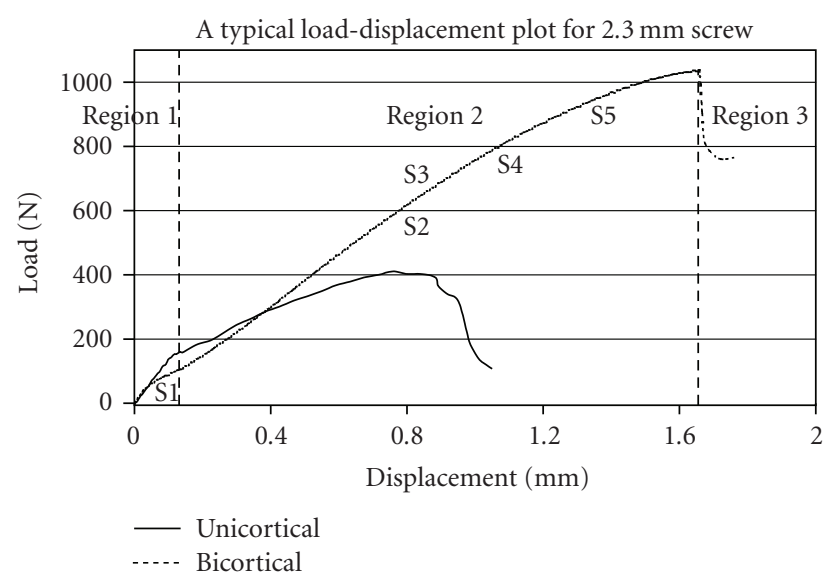

Figure 5: Graph showing typical load-displacement curves for bicortical and unicortical pull-outs. Results were taken for screws with a $2.3 \mathrm{~mm}$ major diameter and a $1.0 \mathrm{~mm}$ pitch. Three different regions are denoted from which specimens were taken for polishing.

TABLE 4: Load and displacement results for the screw pull-out experiments.

\begin{tabular}{llcc}
\hline & & Mean & St. Dev. \\
\hline \multirow{2}{*}{ Bicortical screw } & Global maximum load (N) & 975.02 & 83.15 \\
& Displacement (mm) & 1.61 & 0.20 \\
\multirow{2}{*}{ Unicortical screw } & Global maximum load (N) & 372.96 & 38.77 \\
& Displacement (mm) & 0.96 & 0.24 \\
\hline
\end{tabular}

by approximately $8 \%$. This is in contrast to results from the current study which shows about a $67 \%$ increase. Theses studies differed in thetested material, the screw type/geometry, the pull-out rate, and the flex within the experimental setup, which all can alter the pull-out force [25]. While Ryken focused on cervical plate screws, the current study is deemed more appropriate pertaining to screws used in the rigid fixation of mandibular fractures.

\subsubsection{Polishing}

Five different samples, labeled S1, S2, S3, S4, and S5 (see Figure 5), were sectioned and polished to reveal their interior damage state. Specimen S1 showed no observed microdamage at magnification of 400X. S1 lies within an elastic region (Region1) which exhibits linear behavior. Specimen S2 was just past the elastic region but it was not associated with macro surface cracks (Figure 6(a)). The image of specimen S3 is shown in Figure 6(b). Shearing of the cortical material can be seen near the top part of the image. With increased load the screw is slowly pulled out until the uppermost thread chips off the material (Figure 6(b)). For specimen $\mathrm{S} 4$, in addition to the failure seen in $\mathrm{S} 3$, the bone undergoes microcracking (Figure 6(c)) at the thread immediately inferior to the uppermost thread.

At higher loads, near S5, microcracking also takes place in the lower cortical layer as well (Figure 6(d)). It is worthy to mention, from the polished specimens, that crack formation 


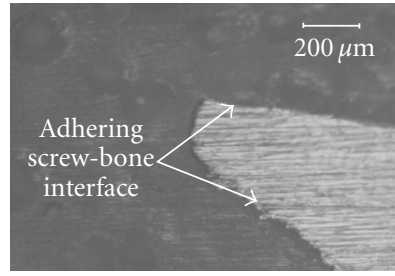

(a)

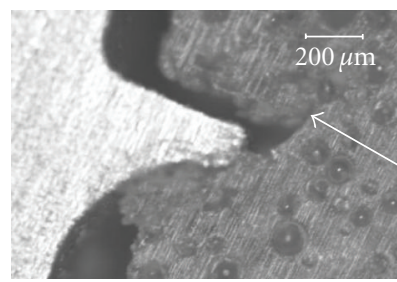

(d)

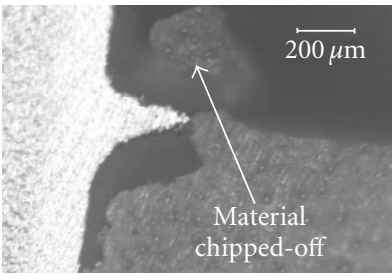

(b)

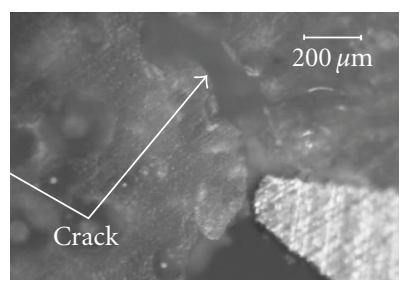

(c)
FIGURE 6: Images of polished specimens showing the thread-block interface for the following loads: (a) $566.4 \mathrm{~N}$ and magnification of 200X (specimen S2), (b) $684.6 \mathrm{~N}$ and magnification of $50 \mathrm{X}$ (specimen S3), (c) $783.9 \mathrm{~N}$ and magnification of 200X (specimen S4), and (d) $891.3 \mathrm{~N}$ and magnification of $100 \mathrm{X}$ (specimen S5).

always seems to start near the uppermost thread in both the upper and lower cortical layers.

\subsubsection{Numerical Screw Pull-out}

General stress contours for all screws analyzed are first discussed. Figure 7(a) shows a typical distribution of von Mises stress in the block for the numerical analysis using a load of $600 \mathrm{~N}$. Stress concentration occurs in the block material immediately surrounding the screw threads with the highest stress region observed near the top surface of the block. This finding is consistent with another work by the authors in which 3D finite element modeling was performed on a fractured mandible that was fixated with a common plating configuration [15]. It is also consistent with damage occurring near the top surface as found in the above microscopic studies. In the current work, the stress concentration on the top surface was found to be traversing in a direction diagonal to the block. This was clear at higher loads and conforms to experimental observations as almost all of the bicortical, and some of the unicortical specimens, failed with diagonal surface cracks.

Figures 7(b) and 7(d) show plots depicting stress distribution along diagonal and frontal sectional views. The stress is seen to concentrate along the screw-block interface and in the general vicinity of the screw. Measurements suggest that inserted surgical screws separated by a diameter or more would have little interaction between their respective stress fields.

Figure 7(c) shows a typical volumetric contour plot. The plot shows only the material surrounding the screw that is stressed above a certain threshold of von Mises stress. As mentioned in earlier sections, most test failures occur in such a way that the screw comes off from the block with cortical material entrapped between its threads. This type of failure was hence referred to as "cylindrical failure." Figures 7(b), $7(\mathrm{c})$, and $7(\mathrm{~d})$ show the screw surrounded by a cylindrical envelope of the block material with the highest stress. This is consistent with the experimentally observed cylindrical failures.

Seven different parametric cases were studied using the finite element model for both bicortical and unicortical setups. Each case had a different combination of major diameter, pitch, and thread depth. The base case represents a major diameter of $2.3 \mathrm{~mm}$, a pitch of $1.0 \mathrm{~mm}$, and a screw depth of $0.3 \mathrm{~mm}$. All of these base case numbers are standard for surgical screws (taken with permission from Stryker Corporation, Kalamazoo, Mich, USA). Note that every time a parameter (e.g., major diameter) was varied, all other parameters were held constant (e.g., pitch and screw depth). For a given case, von Mises stresses are interrogated from the highest stress level, which occurs near the top screw thread, down to a stress level, which completely envelops the screw. At this stress level, which we term the "envelope stress," the stress at any material point within this envelope will be equal or higher than this value up to the maximum stress level near the uppermost thread. The envelope stress essentially describes the weakest point before cylindrical failure, andit is used here to weigh the varying screw parameters. A lower value of the "envelope stress" is desirable when considering the different bone screws.

The plots in Figure 8 depict the effect of screw parameters of both bicortical and unicortical screws on the screw envelope stress. Figure 8 (a) shows the effect of the different parameters on the unicortical pull-out. The most optimal conditions pertaining to envelope stress were a larger major diameter and a larger thread depth. Interestingly, it was found that a small screw diameter also has a desirable "envelope stress," but it was associated with a higher stress measure at the top surface when compared to the effect of other parameters. Change in screw pitch affected the envelope stress less than the other screw parameters.

Figure 8(b) shows the effects of various screw parameters on the pull-out envelope stress of the bicortical samples. Optimal conditions suggest a smaller pitch and a large major diameter. This is different than in the unicortical results, where the pitch did not largely affect the stress. A deeper thread depth seems to have lower "envelope stress," but it was found to have very high localized stress at the top surface of the block, again differing from the unicortical screw results. A deeper thread depth appears to be unfavorable in the bicortical case. Similar to the unicortical sample conclusion, a large screw diameter has a positive effect with a low stress value for the "envelope stress" plot.

\subsection{Mandibular Finite Element Analysis}

Results for the forces transmitted upon mastication from the fixation plate to the screw implant were obtained for the four screw implants most proximal to the fracture (Table 5). The $x, y$, and $z$ axes correspond to the orthotropic material axes described in Section 2.2.2, with the positive $y$ direction 

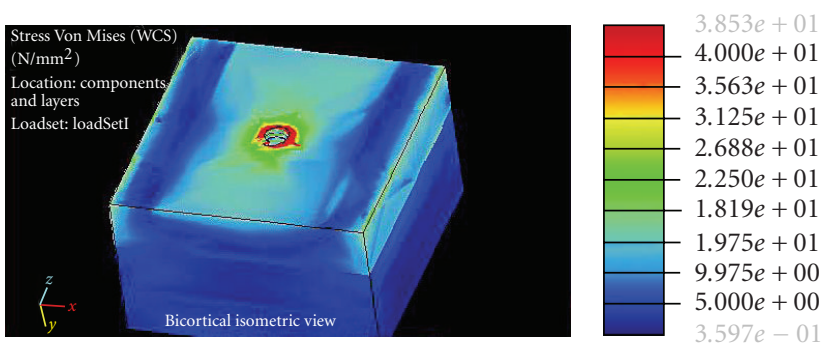

(a)
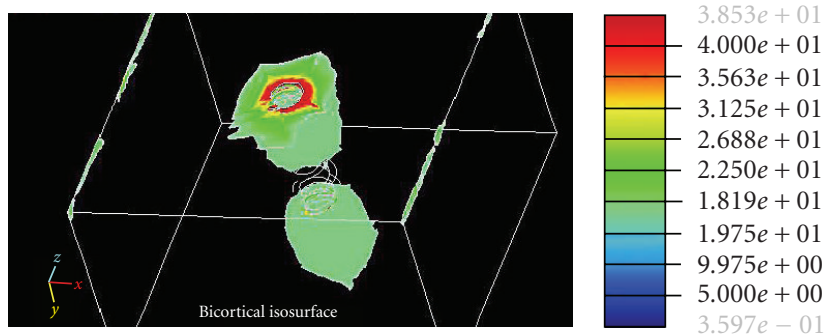

(c)
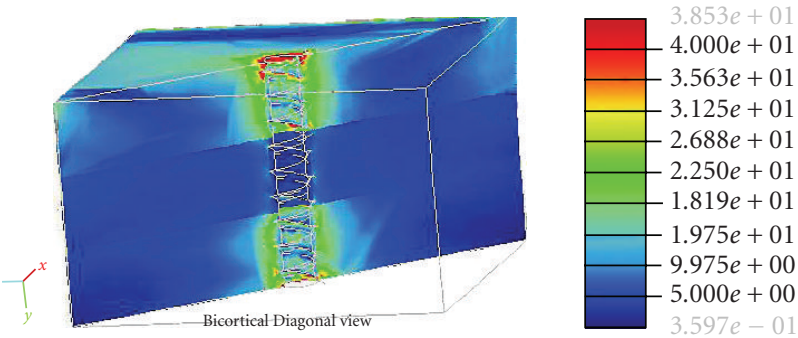

(b)
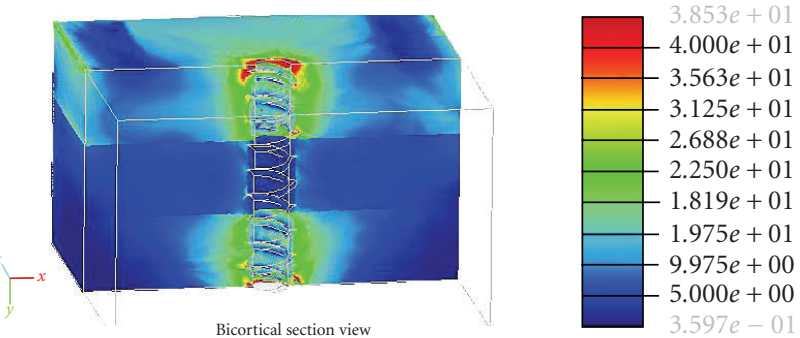

(d)

FIGURe 7: Plots of von Mises stress (MPa) in a typical trilaminate block. The four views shown are (clockwise from top-left): (a) isometric view, (b) diagonal section view, (c) volumetric contours, and (d) section view.

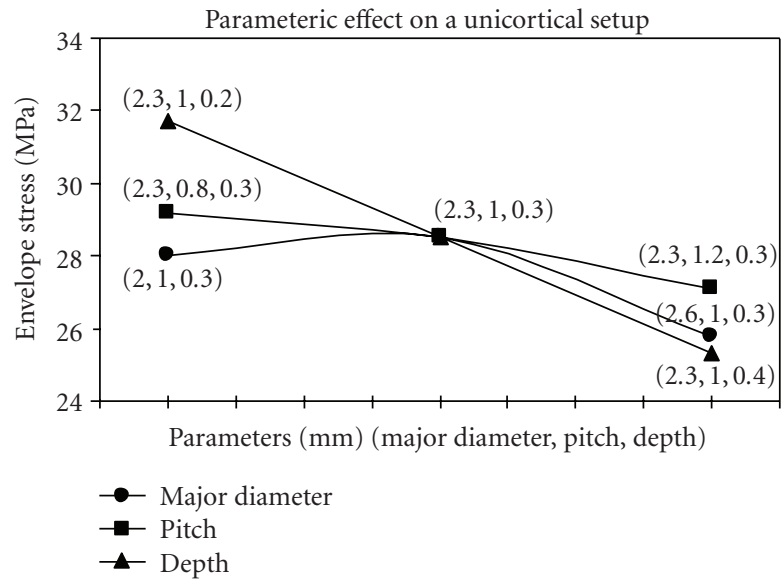

(a)

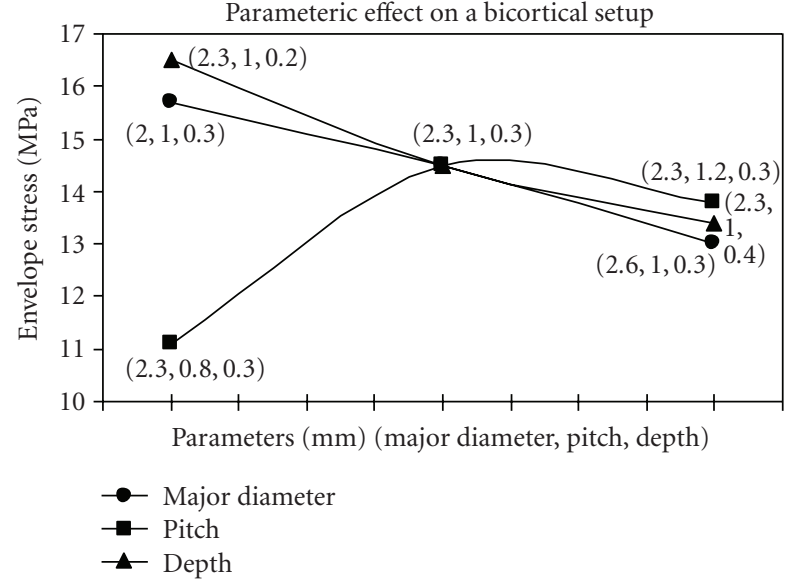

(b)

FIGURE 8: Plots showing the "envelope stress" for unicortical and bicortical setups.

corresponding to the pull-out direction (normal to the bone surface). A negative $y$ direction refers to a "pushing in" of the screw implant. Only the maximum "pulling out" force was considered for the screw FEA submodel.

These results were translated into relevant loadings and applied to a threaded screw implant submodel in order to compare the effect of different screw configurations on stresses induced in the bone in which they are seated. The study was undertaken to gather information that will aid the design and use of screw implants in rigid internal fixation of mandibular fractures. The results gathered are expected to be more relevant than linear screw pull-out numerical analyses.

The results of the mandibular FEA show the forces applied to the four screw implants most proximal to the fracture. The maximum pull-out force seen from the current
TABLE 5: Force components (N) applied to the screw implants by the fixation plate in FEA of a fractured and fixated mandible. The $x$-direction is along the length of the mandible, $y$ is normal to the bone plane, and the $z$-direction is their cross product.

\begin{tabular}{lccc}
\hline Screw location & $x$ & $y$ & $z$ \\
\hline Superior posterior medial & 55.3 & -13.2 & 39.4 \\
Superior anterior medial & -57.6 & 8.9 & -26.3 \\
Inferior posterior medial & -67.6 & -16.4 & 22.2 \\
Inferior anterior medial & 51.0 & 21.8 & -30.0 \\
\hline
\end{tabular}

mandibular FEA is $21.8 \mathrm{~N}$. This is considerably less than the forces leading to failure in the experimental pull-out analyses. We see further that the transverse forces (in the $x$ 


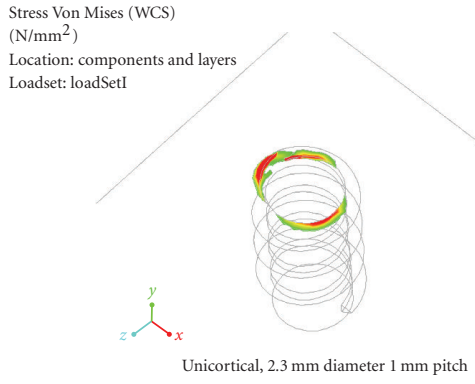

(a)

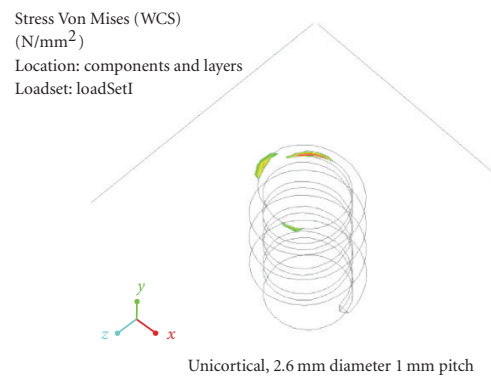

(c)

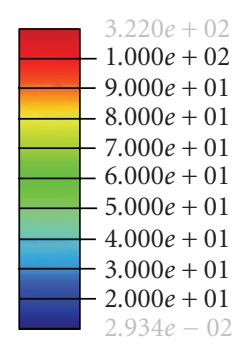

Stress Von Mises (WCS) $\left(\mathrm{N} / \mathrm{mm}^{2}\right)$ Location: components and layers Loadset: loadSetI

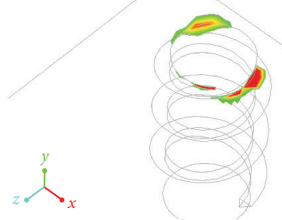

Unicortical, $2.3 \mathrm{~mm}$ diameter $1.2 \mathrm{~mm}$ pitch

(b)
$3.220 e+02$ $1.000 e+02$ $9.000 e+01$ $-8.000 e+01$ $7.000 e+01$ $6.000 e+01$ $5.000 e+01$ $4.000 e+01$ $3.000 e+01$ $2.000 e+01$
$2.934 e-02$ $2.934 e-02$ 
conducive to results unaffected by implant insertion length. While the loading of the current study is considered more relevant than previous works, the effect of bone quality on the results is not within the current scope.

Readers should be informed in putting too much confidence into quantitative results from $\mathrm{FE}$ analyses of this type. There is a large range of possible inputs into mandibular FEA considering the different bone material properties, bite force magnitudes, fracture locations, and jaw geometries among patients, to name just a few variable patient parameters. Nonetheless, comparisons between different screw configurations based on peak stress and the amount of material that is predicted to fail given a failure stress threshold offer qualitative insight that can aid both screw design and craniomaxillofacial surgical practice.

\section{Conclusions}

The current study used experimental screw pull-out tests, finite element analysis (FEA) of detailed screw pull-out models, and FEA of a fractured and fixated mandible to determine the effect of bone screw design parameters on stresses generated in bone surrounding screw implants used in patients treated with open reduction and internal fixation (ORIF) of mandible fractures. Results from the experimental and numerical screw pull out tests correlated well. The parametric numerical analyses gave differing conclusions pertaining to screw thread depth and pitch for the unicortical and bicortical screws but concluded that the major diameter is relevant in reducing high stress in the surrounding bone. Results of the mandibular FEA suggest that transversely applied forces are dominant upon the implant. The screw FEA submodel determined that there are lower stresses generated around a $2.6 \mathrm{~mm}$ unicortical screw than those surrounding a $2.3 \mathrm{~mm}$ bicortical screw when subjected to clinically relevant loading. This suggests that better fixation can be achieved while avoiding bicortical drilling by increasing the major diameter of unicortical bone screws used in ORIF.

\section{Acknowledgment}

The authors acknowledge the support of Stryker-Leibinger Inc. for STL and NC.

\section{References}

[1] S. Tada, R. Stegaroiu, E. Kitamura, O. Miyakawa, and H. Kusakari, "Influence of implant design and bone quality on stress/strain distribution in bone around implants: a 3dimensional finite element analysis," International Journal of Oral \& Maxillofacial Implants, vol. 18, no. 3, pp. 357-368, 2003.

[2] A. S. Murthy and J. A. Lehman Jr., "Symptomatic plate removal in maxillofacial trauma: a review of 76 cases," Annals of Plastic Surgery, vol. 55, no. 6, pp. 603-607, 2005.

[3] M. A. C. Gabrielli, M. F. R. Gabrielli, E. Marcantonio, and E. Hochuli-Vieira, "Fixation of mandibular fractures with $2.0 \mathrm{~mm}$ miniplates: review of 191 cases," Journal of Oral and Maxillofacial Surgery, vol. 61, no. 4, pp. 430-436, 2003.
[4] J. Lamphier, V. Ziccardi, A. Ruvo, and M. Janel, "Complications of mandibular fractures in an urban teaching center," Journal of Oral and Maxillofacial Surgery, vol. 61, no. 7, pp. 745-749, 2003.

[5] E. C. Benzel, "Implant-bone interfaces," in Biomechanics of Spine Stabilization: Principles and Clinical Practice, E. C. Benzel, Ed., pp. 127-134, McGraw-Hill, New York, NY, USA, 1995.

[6] R. Skinner, J. Maybee, E. Transfeldt, R. Venter, and W. Chalmers, "Experimental pull-out testing and comparison of variables in transpedicular screw fixation. A biomechanical study," Spine, vol. 15, pp. 195-201, 1990.

[7] T. C. Ryken, J. D. Clausen, V. C. Traynelis, and V. K. Goel, "Biomechanical analysis of bone mineral density, insertion technique, screw torque, and holding strength of anterior cervical plate screws," Journal of Neurosurgery, vol. 83, no. 2, pp. 324-329, 1995.

[8] T. C. Ryken, V. K. Goel, J. D. Clausen, and V. C. Traynelis, "Assessment of unicortical and bicortical fixation in a quasistatic cadaveric model: role of bone mineral density and screw torque," Spine, vol. 20, no. 17, pp. 1861-1867, 1995.

[9] D. J. Maiman, F. A. Pintar, N. Yoganandan, et al., "Pullout strength of Caspar cervical screws," Neurosurgery, vol. 31, no. 6, pp. 1097-1101, 1992.

[10] J. M. Boyle, D. E. Frost, W. L. Foley, and J. J. Grady, "Torque and pullout analysis of six currently available self-tapping and "emergency" screws," Journal of Oral and Maxillofacial Surgery, vol. 51, no. 1, pp. 45-50, 1993.

[11] J. H. Phillips and B. A. Rahn, "Comparison of compression and torque measurements of self-tapping and pretapped screws," Plastic and Reconstructive Surgery, vol. 83, no. 3, pp. 447-456, 1989.

[12] T. Cox, M. W. Kohn, and T. Impelluso, "Computerized analysis of resorbable polymer plates and screws for the rigid fixation of mandibular angle fractures," Journal of Oral and Maxillofacial Surgery, vol. 61, no. 4, pp. 481-487, 2003.

[13] J. R. Fernández, M. Gallas, M. Burguera, and J. M. Viaño, “A three-dimensional numerical simulation of mandible fracture reduction with screwed miniplates," Journal of Biomechanics, vol. 36, no. 3, pp. 329-337, 2003.

[14] A. Wagner, W. Krach, K. Schicho, G. Undt, O. Ploder, and R. Ewers, "A 3-dimensional finite-element analysis investigating the biomechanical behavior of the mandible and plate osteosynthesis in cases of fractures of the condylar process," Oral Surgery, Oral Medicine, Oral Pathology, Oral Radiology \& Endodontics, vol. 94, no. 6, pp. 678-686, 2002.

[15] S. T. Lovald, T. Khraishi, J. Wagner, B. Baack, J. Kelly, and J. Wood, "Comparison of plate-screw systems used in mandibular fracture reduction: finite element analysis," Journal of Biomechanical Engineering, vol. 128, no. 5, pp. 654662, 2006.

[16] S. T. Lovald, J. Wagner, T. Khraishi, J. Kelly, J. Wood, and B. Baack, "Finite element analysis of screw-plate systems for fixation of parasymphyseal fractures of the mandible," Journal of Mechanics, vol. 23, no. 1, pp. 69-77, 2007.

[17] N. Chaudhary, S. T. Lovald, J. Wagner, T. Khraishi, J. Kelly, and J. Wood, "Modeling of screw-plate systems for mandibular fracture repair," in Proceedings of the ASME International Mechanical Engineering Congress and Exposition Conference (IMECE '04) Bioengineering Division, Bioengineering Division, Anaheim, Calif, USA, November 2004, paper no. 62256.

[18] S. T. Lovald, J. Wagner, T. Khraishi, J. Kelly, J. Wood, and B. Baack, "Finite element analysis of fixation plates for mandibular fracture reduction," in Proceedings of the ASME 
Summer Bioengineering Conference (SBC '05), pp. 1406-1407, Vail, Colo, USA, June 2005.

[19] C. L. Schwartz-Dabney and P. C. Dechow, "Variations in cortical material properties throughout the human dentate mandible," American Journal of Physical Anthropology, vol. 120, no. 3, pp. 252-277, 2003.

[20] T. W. P. Korioth, D. P. Romilly, and A. G. Hannam, "Threedimensional finite element stress analysis of the dentate human mandible," American Journal of Physical Anthropology, vol. 88, no. 1, pp. 69-96, 1992.

[21] R. G. Craig and F. A. Peyton, "Elastic and mechanical properties of human dentin," Journal of Dental Research, vol. 37, no. 4, pp. 710-718, 1958.

[22] A. Bailon-Plaza and M. C. H. van der Meulen, "Beneficial effect of moderate, early loading and adverse effects of delayed or excessive loading on bone healing," Journal of Biomechanics, vol. 36, no. 8, pp. 1069-1077, 2003.

[23] G. S. Tate, E. Ellis III, and G. Throckmorton, "Bite forces in patients treated for mandibular angle fractures," Journal of Oral and Maxillofacial Surgery, vol. 54, no. 7, pp. 734-736, 1994.

[24] H. Gray, Gray's Anatomy, Barnes and Noble Books, New York, NY, USA, 15th edition, 1995.

[25] A. Shirazi-Adl, M. Dammak, and D. J. Zukor, "Fixation pull-out response measurement of bone screws and poroussurfaced posts," Journal of Biomechanics, vol. 27, no. 10, pp. 1249-1258, 1994.

[26] H. M. Frost, "A 2003 update of bone physiology and Wolff's law for clinicians," The Angle Orthodontist, vol. 74, no. 1, pp. 3-15, 2003.

[27] D. van Steenburgh, U. Lekholm, C. Bolender, et al., "Applicability of osseointegrated oral implants in the rehabilitation of partial edentulism: a prospective multicenter study on 558 fixtures," Journal of Oral and Maxillofacial Surgery, vol. 5, no. 3, pp. 272-281, 1990. 

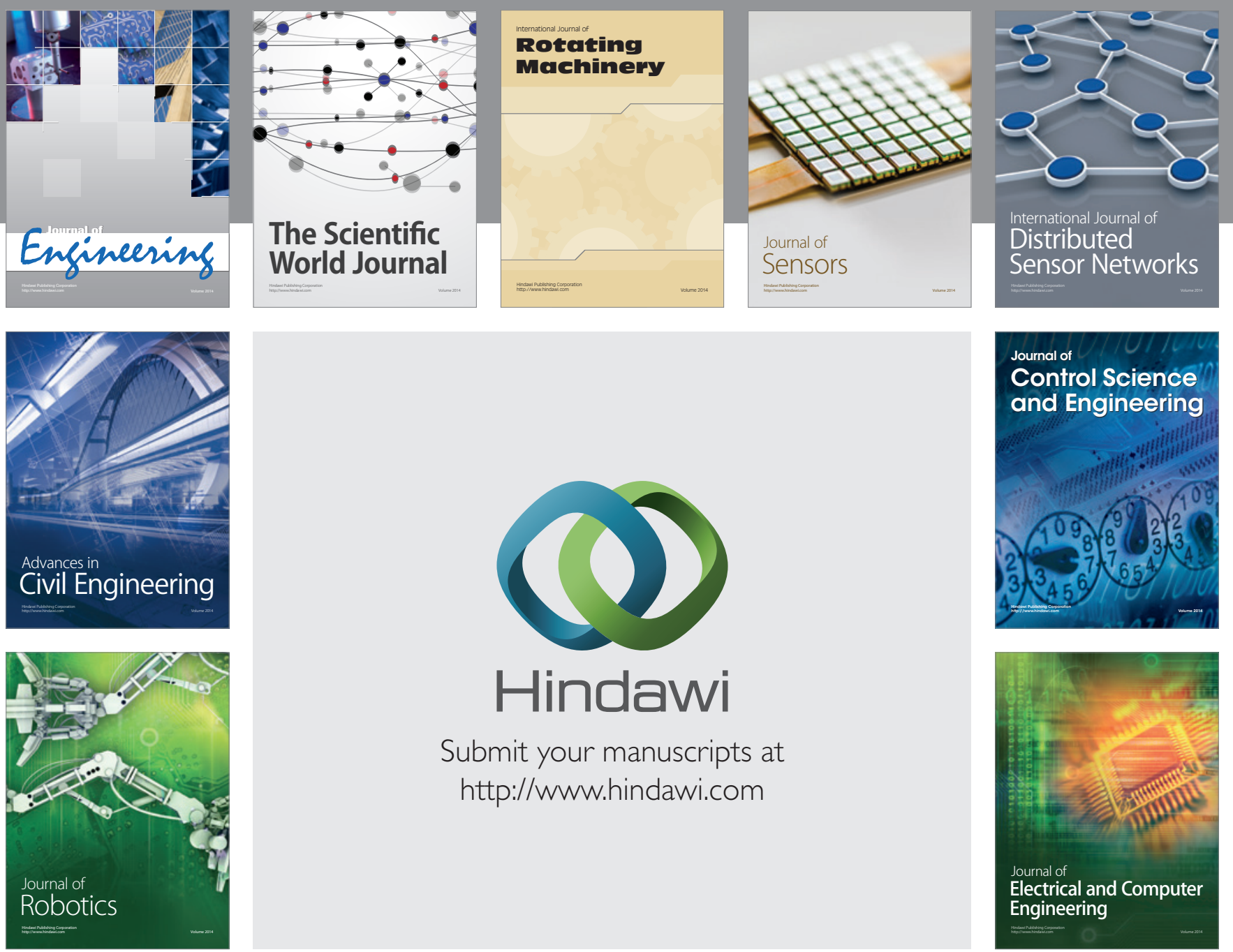

Submit your manuscripts at

http://www.hindawi.com
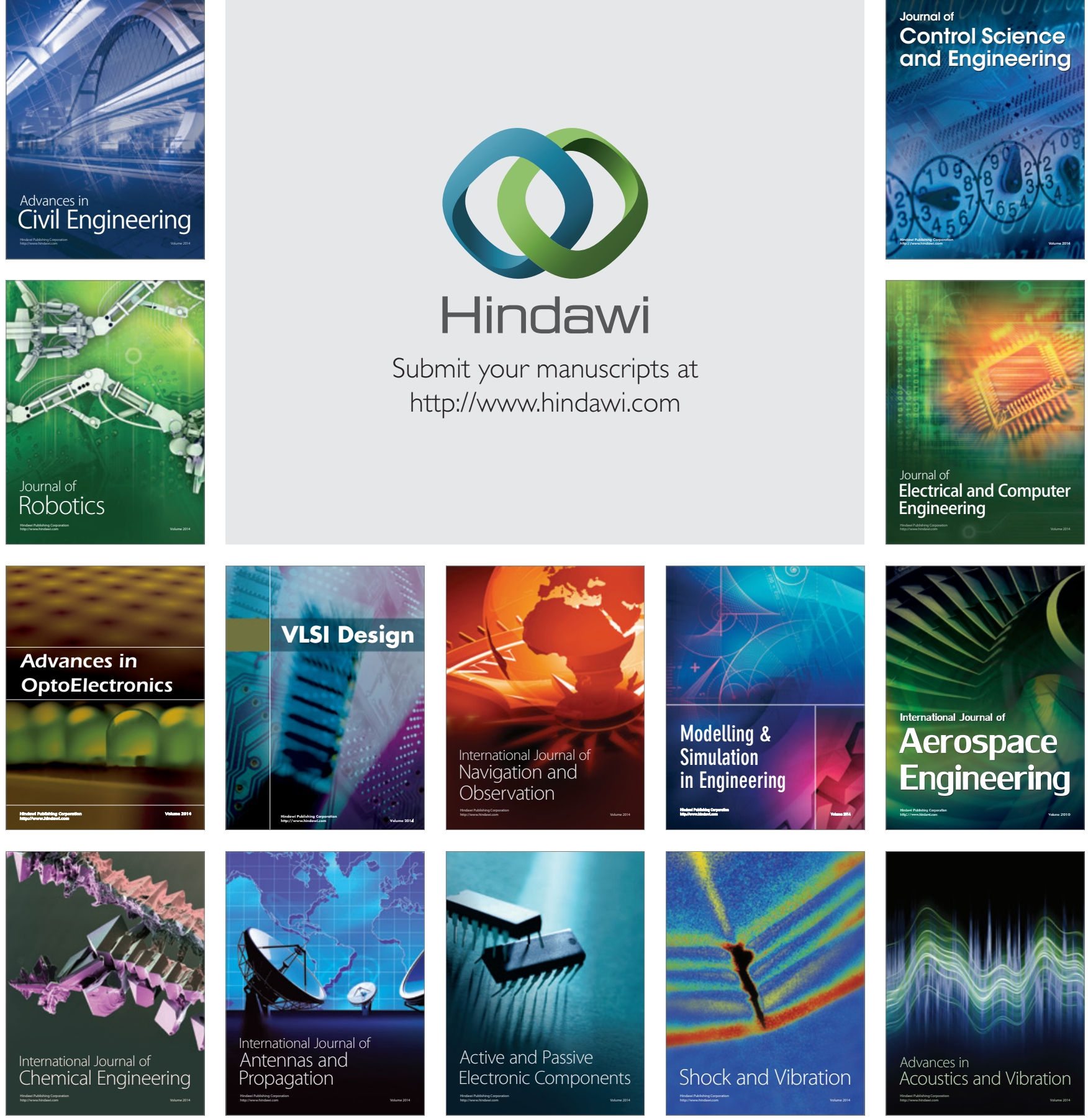